УДК 317

$10.17213 / 2075-2067-2020-3-100-108$

\title{
СЕМЬЯ И ЖИЗНЕННЫЕ ПРОЕКТЫ РОССИЙСКОЙ МОЛОДЕЖИ В ЛОГИКЕ ПАРАДОКСАЛЬНОГО АНАЛИЗА
}

\author{
(C) 2020 г. А. В. Верещцагина, М. В. Герасимов
}

\section{Южный федеральный университет, г. Ростов-на-Дону, Россия}

Цель исследования. Жизненные проекты молодежи как предмет сочииологической рефлексии представляют чрезвычайный интерес для сочиологии. Молодежь стоит на «пороге» будущего и еще только конструирует его образ. Этот образ будущзего является системообразующим в пространстве конструирования жизненного мира молодежью, но в современной реальности он утратил четкие очертания, а сам характер жизненного проектирования перестал носить линейную и целостную направленность.

Методология исследования представлена феноменологическим направлением в соииологии и парадигмой сочиологии жсизни.

Результаты. $B$ данной статье не сами жизненные проекты выступают предметом социологической рефлексии, а механизм их формирования, и с этой точки зрения авторы обратились к одному из традиционных и наиболее влиятельных факторов в системе социализации молодежи - семье. В диалектике парадоксального подхода обосновывается, что семья уже утратила свои доминантные позиции в конструировании жсизненных проектов молодежси и перестала быть идеальным образом и пространством трансляиии через него эффективной траектории жизненного проектирования. Но она продолжает «играть» эту исторически сложившуюся роль демиурга жизненного мира молодежи, оказывая зачастую обратное от положстельного эффекта воздействие, формируя у нее инфантильные установки и искаженные представления о реальности, что затрудняет механизм адаптации к ней у части российской молодежи.

Ключевые слова: семья; молодежь; жизненные проекты; жизненный мир; жизненное проектирование; парадоксальная реальность.

\section{FAMILY AND LIFE PROJECTS OF RUSSIAN YOUTH IN THE LOGIC OF PARADOXICAL ANALYSIS}

\section{(C) 2020 A. V. Vereshchagina, M. V. Gerasimov}

\section{Southern Federal University, Rostov-on-Don, Russia}

The purpose of the study is youth life projects as a subject of sociological reflection are of extreme interest to sociology. Young people are on the "threshold» of the future and are still only constructing its image. This image of the future is system-forming in the space of constructing the life world by young people, but in modern reality it has lost its clear outline, and the very nature of life design has ceased to be linear and holistic.

Research methodology the phenomenological direction in sociology and the paradigm of the sociology of life.

Results. In this article not life projects themselves are the subject of sociological reflection, but the mechanism of their formation and from this point of view the authors turned to one of 
the traditional and most influential actors in the system of youth socialization - the family. In the dialectic of the paradoxical approach, it is substantiated that the family has already lost its dominant position in the construction of youth life projects and has ceased to be an ideal way and space to transmit through it an effective trajectory of life design. But she continues to "play» this historically established role of the demiurge of the life world of youth, often having the opposite effect from the positive effect, forming her infantile attitudes and distorted ideas about reality, which makes it difficult for some of the Russian youth to adapt to it.

Key words: family; youth; life projects; life world; life design; paradoxical reality.

Введение: постановка проблемы и теоретические основания исследования. Жизненный мир, жизненное проектирование, жизненные проекты - категории социологической науки, все чаще попадающие в фокус социологического внимания и дискурса в самых различных ракурсах в отношении различных социальных групп [1]. Являясь предметным полем феноменологического направления в социологии [2], указанные категории привлекают к себе внимание исследователей, работающих в методологической парадигме социологии жизни [3] и осознающих с одной стороны их значимость в социокультурной динамике общества, в котором сама реальность предстает как конструируемая в зависимости от восприятия этой реальности, а с другой - изменение самого механизма конструирования жизненного мира как целостности, разрыв которой означает негативный сценарий развития индивида, социальной группы. В.Н. Волков так описывает эту ситуацию: «Если целостность распадается, это означает для человека крайне тяжелое состояние, когда он воспринимает себя не как единое целое, а как состоящее из нескольких частей. Человек не может адекватно себя вести в соответствии с ситуацией, он стремится создать для себя новый мир, в котором пытается восстановить целостность, начинает строить объяснительные схемы» [4].

По сути жизненный мир - энергетическое поле человека, его среда, его защита, условие и основание развития, но в условиях современного информационного общества распад жизненного мира как целостности наиболее часто угрожает индивидам и социальным группам, поскольку современный мир стал неустойчивым, стремительно меняющимся, наполненным рисками и неоп- ределенностью. Самореализация и самоутверждение в таком мире требуют от индивида особых качеств и способностей, особых стратегий и характеристик, укладывающихся в категорию мобильности - важнейшего индикатора современной компетентности [5], современного мира как «мобильного мира» и человека как «человека мобильного» [6].

Жизненный мир, с точки зрения Ж. Т. Тощенко, представляет собой совокупность базовых смыслов жизни человека, в которых выражаются глубинные основы его бытия [7]. Ш.И. Алиев жизненный мир рассматривает с позиций деятельностного подхода, интерпретируя его как преломленную в практической деятельности индивида реальность, восприятие которой в свою очередь детерминирует жизненное проектирование, индикативной единицей измерения которого выступают жизненные проекты как «совокупность задач и средств их реализации, направленных на достижение запланированной жизненной цели (или целей)» [8]. В рамках предложенной Ш.И. Алиевым теоретической конструкции фигурирует такое понятие, как система жизненного проектирования. Ее данный ученый определяет через совокупность связанных между собой жизненных проектов. На этом основании жизненное проектирование предстает в виде подсистемы, от которой зависит формирование жизненного мира индивида как целостной системы.

Как видим, в различных подходах и интерпретациях жизненного мира индивидацентральной категорией выступает целостность, в которой отражаются глубинные смыслы бытия человека. И жизненные проекты являются элементом, структурирующим и задающим вектор динамики этой целостности - жизненного мира, многообразие кото- 
рого можно изучать по-разному, но в рамках социологической рефлексии целесообразно это делать через анализ жизненных планов и проектов различных социальных групп. Молодежь как социально-демографическая группа, находящаяся на грани двух специфических миров - мира детства и мира взрослых, имеет особый статус в социологических исследованиях. Его можно условно назвать прогностическим, поскольку устремленная в будущее, планирующая свое настоящее как проекцию будущих шагов в различных сферах жизнедеятельности (семейной, образовательной, профессионально-трудовой и т.д.), молодежь тем самым задает индикаторы будущего состояния локального и макросоциального мира. И потому представления о мире, которые отражаются в жизненном мире молодежи, ее планы в проекции видения своего будущего (или отсутствия такового, что зачастую характеризует современную молодежь и находит выражение в коротких жизненных проектах [9]) представляют чрезвычайный научный интерес и значимость с точки зрения получения социального знания не только о молодежи как субъекте общественных отношений, но и обществе, в котором она реализует свою субъектность в виде формирования и претворения в жизнь своих планов и проектов.

Таким образом, жизненный мир молодежи, его формирование и изменение не только отражают реалии социокультурного бытия социума, но и позволяют заглянуть за пределы настоящего и сформировать возможные сценарии будущей траектории социокультурной динамики общества. Будущее предсказуемо, прогнозируемо, во всяком случае, на уровне возможных альтернатив (моделей, сценариев) развития [10], а, значит, оно управляемо. Одним из способов управления будущим выступает возможность социальной регуляции самого процесса конструирования молодежью жизненного мира, который происходит за счет формирования и реализации жизненных проектов, но для этого необходимо иметь полноценное научное представление о жизненном проектировании молодежи и методологии его исследования, факторах, детерминирующих характер и динамику жизненного проектирования, основных акторах его формирования.
В данной статье на уровне постановки самой проблемы раскрывается лишь один из многочисленных сюжетов данного направления в изучении российской молодежи в контексте ее жизненного проектирования, и этот сюжет связан с оценкой роли семьи в данном процессе. Какова эта роль в условиях современной, динамично меняющейся реальности, в которой самопроектирование стало основным механизмом, ресурсом и индикатором социальной адаптации и социального успеха индивида, социальной группы? Является ли эта роль определяющей? Что может сегодня семья предложить молодежи в плане «рецептов» жизненной самореализации и достижения социального успеха? Является ли семья авторитетом для молодых людей, конструирующих свой жизненный мир в том мире, в котором уже глобальное и локальное, виртуальное и реальное, стабильное и нестабильное, постоянное и изменчивое, движение и покой утратили свои константные признаки и четкие границы?

В меняющемся мире меняется всё и вся, а потому заданные выше вопросы не являются праздными и очевидными с точки зрения имеющихся на них ответов. Размышляя на уровне антиномий как основания парадоксального анализа, мы постараемся показать и обосновать эту точку зрения о высокой степени автономности жизненного проектирования молодежи и неоднозначного (во многом парадоксального) влияния на данный процесс семьи, причем парадоксальность этого влияния вполне закономерна и естественна с учетом социокультурного контекста, в котором разворачиваются многогранные, противоречивые и неопределенные жизненные процессы и проекты.

Роль семьи в формировании жизненных проектов российской молодежи. Далеко не всегда люди готовы принять мир, каким он есть, но и мир, какой он есть, не всегда является таким, каким его представляют. И тогда возможное и невозможное, реальное и ирреальное, позитивное и негативное предстают в виде конструктов, в любой момент способных поменяться местами. В логике парадоксального анализа это выражается в формуле, что невозможное может стать возможным, если найти логику в том, что 
представляется на данный момент как невозможное. В логике парадоксального суждения в контексте социологической рефлексии парадоксальным может считаться любое явление социального мира, которое расходится со сложившимися в социуме представлениями о самой социальной реальности.

В предметном поле данной статьи ситуация парадоксальности нам видится в той роли, которую семья традиционно играла в жизни российской молодежи, в конструировании ее жизненного мира и, что важнее всего, продолжает играть в логике собственных представлений о социализации и воспитании молодежи, необходимости ее «вести за ручку» по жизни, и, будучи устойчивыми, эти представления воспроизводятся, вклиниваясь в жизненное проектирование российской молодежи, зачастую не самым удачным образом. Но самое главное происходит потом, когда молодежь становится объектом обвинений со стороны взрослого сообщества, сконцентрированных в семьях, не понимающих, что парадокс заключается в следующем: они же и стали первопричиной жизненных неудач и неблагополучия воспитанной ими молодежи.

Данная оценка ни коим образом не является абсолютной и относящейся ко всей молодежи. Размышляя на уровне сложившейся в целом в стране ситуации, характеризующейся жизненной неустроенностью молодежи и отнесением ее к группе наивысшего риска среди остальных социальных групп в мире социально-профессионального становления [11], семейной самореализации [12], мы стремимся сформулировать проблему с позиций выбранного ракурса исследования, чтобы дойти до сути, найти источник жизненного неблагополучия той молодежи, которой не удалось реализовать свои жизненные планы или, как минимум, сконструировать их. Таких в современном российском обществе немало, и согласно мнению исследователей одна из причин кроется в социальной инфантильности молодежи [13], которая в свою очередь формируется прежде всего в пространстве семейного воспитания.

Да, жизненный мир человека - это результат влияния целой группы факторов объективного и субъективного свойства, взаимосвязанных между собой и проявляющихся в жизни каждого человека уникальным образом, ведь нет одинаковых судеб, одинаковых биографий, и жизненный путь каждого индивида - следствие индивидуальной траектории движения по шкале «самосозидание самотворение - самоосуществление». Тем не менее, есть законы социетальной динамики, и они определяют значимость институциональных факторов в воспроизводстве социальной реальности, а также социальных практик и отношений. К числу основных акторов формирования жизненных проектов молодежи следует относить базовые институты, ответственные за процесс социализации молодого поколения. Важнейшим институтом социализации молодежи в социологии традиционно принято считать семью, хотя в современном обществе набирает вес тенденция, связанная с вытеснением семьи из числа доминантных агентов социализации, поскольку социализационный вес набирают иные социальные институты, ставящие под вопрос монополию семьи на воспитание подрастающего поколения. Это и СМИ, и Интернет-среда с ее сетевыми площадками и новыми медийными возможностями, и компании сверстников, и молодежные субкультуры. Тем не менее, не вызывает сомнений тот факт, что в семье по-прежнему происходит физическое, духовное и эмоциональное становление личности, определяются мировоззренческие ориентиры и поведенческие модели, на основе которых осуществляется и реализуется жизненное проектирование. Иными словами, влияние семьи является важнейшим в процессе формирования системы личностного проектирования жизни представителями молодежной группы. Как содержательная часть жизненных проектов молодежи, так и тактика их реализации также определяется преимущественно в семье. В жизненных проектах молодежи находят отражение такие характеристики семьи, как ее структура, образ жизни, социальный статус в совокупности параметров образовательного, социокультурного, профессионального, материального уровня родителей и близких родственников.

Поведение родителей и других членов семьи во многом определяет отношение представителей подрастающего поколения к окружающей действительности, что в свою 
очередь оказывает воздействие на формирование их жизненных проектов. Самосознание молодых людей формируется не только посредством прямого научения и подражания, что обычно характерно для стадии детства, но и путем соотнесения собственного индивидуального опыта с образом жизни родителей. Таким путем на данном этапе личностного развития индивида осуществляется усвоение базовых норм и ценностей. Несмотря на определенные сложности в функционировании института семьи в современном российском обществе, его кризисное состояние, он и по сей день характеризуется наличием максимальных возможностей и средств воздействия на сознание и поведение молодежи, формирование ее ценностного мира и адаптационного потенциала. Но эти максимальные возможности не всегда используются эффективно и благоприятно влияют на жизненную самореализацию молодежи. Так, можно привести пример с формированием жизненных проектов молодежи в сфере профессионального развития. Не секрет, что для многих из числа представителей молодежи выбор профессии не является сугубо самостоятельным актом, и этот выбор зачастую делают родители, которым «виднее», которым «удобнее» устроить профессиональную жизнь своих детей с ориентацией на прибыльность профессии, ее престижность, востребованность на рынке труда. В результате личностные предпочтения, способности и желания самой молодежи остаются неучтенными при согласии самой молодежи, у которой в итоге формируются искаженные представления о рынке труда, о профессии, о своем профессиональном будущем. И как итог мы получаем высокий процент молодежи, работающей не по специальности [14]. Столкнувшись с реальным миром, молодежь начинает «перекраивать» свои жизненные проекты и планы в сфере профессионализации, и эти усилия не всем приносят удачу, о чем говорят данные по динамике прекариатизации российской молодежи [15].

Таким образом, семья может ориентировать молодого человека на достижение высокой социальной позиции (это может включать, к примеру, выбор профессии, определенного учебного заведения для поступления), а может оставить его без ярко выра- женной установки на достижение жизненных целей и планов. И в том, и другом случае возможны различные конфигурации из значимых для молодежи последствий семейного воздействия, но далеко не факт, что самоопределение, которое делает для молодежи семья, обернется жизненным успехом. Та же ситуация разворачивается и в сфере жизненного проектирования молодежи в сфере семейных отношений. Не секрет, что у многих народов России с традиционным укладом жизни еще сохранились традиции, регламентирующие определяющую роль родителей в выборе спутника жизни, организации свадебного ритуала и т.д. Более того, в некоторых российских регионах (в частности, на Северном Кавказе) парадоксальным образом возвращаются многие из архаических семейных традиций (например, многоженство), что также не может не влиять на жизненные проекты молодых семей, уровень их устойчивости и рискогенности [16].

Современная молодежь живет в уникальном мире с уникальными возможностями. Да, этот мир нестабилен, небезопасен, полон неопределенности, но он глобализируется, границы человеческих возможностей расширяются, и молодежь становится более открытой миру, ощущая свои возможности самоуправления границами собственной жизни, и, как бы парадоксально это ни звучало, именно семья при всех ее благих намерениях зачастую становится источником замыкания молодежи на жизненных мирах, сконструированных не ею.

Иными словами, семья, предлагающая свою траекторию жизненного пути молодежи, лишает ее возможности стать субъектом собственного жизненного проекта. Зачем же потом удивляться несамостоятельности молодежи и ее неспособности к принятию решений, к их воплощению в жизнь? Но этим «удивлением» пронизано научно-общественное пространство дискурса относительно положения молодежи в российском обществе, ее роли в социокультурном воспроизводстве социума.

В целом можно констатировать, что пространство семьи задает социализирующемуся субъекту определенный характер восприятия окружающей действительности в различных модусах, что не может не оказывать воздействие на формирование жизненных стратегий 
представителей молодого поколения, но это воздействие имеет разносторонний, порой противоречивый характер, отражая парадоксальность самой российской реальности.

Вместо заключения. Итак, обращение к особенностям формирования жизненных проектов российской молодежи посредством оценки роли семьи в данном процессе как одного из традиционных и наиболее влиятельных акторов в системе социализации молодежи позволяет констатировать, что семья уже утратила свои доминантные позиции в конструировании жизненных проектов молодежи и перестала быть идеальным образом и пространством трансляции через него траектории эффективного жизненного проектирования. Но она продолжает «играть» эту исторически сложившуюся роль демиурга жизненного мира молодежи, оказывая тем самым обратное от положительного воздействие на молодежь, формируя у нее инфантильные установки и искаженные представления о реальности, в которой действуют свои законы. Эти законы формируются сейчас в условиях информационного общества, в котором от молодежи требуется максимум индивидуальности, самостоятельности и мобильности. Современная российская семья как агент социализации еще не готова к принятию условий этого меняющегося, жесткого и порой жестокого мира, а потому более значимыми акторами в процессе конструирования жизненного мира молодежи становится среда Интернет, социальные сети, субкультурные образования.

Молодежь включена в глобальное информационное пространство, в котором она индивидуализируется и автономизируется, приобретает навыки мобильности как ключевые для самореализации в современном мобильном мире. Семья, стремясь уберечь молодежь от условий турбулентной и непредсказуемой реальности, тем самым ограничивает ее потенциал самопроектирования и самореализации.

Поставленные в статье вопросы и заданные ориентиры их научного разрешения могут стать основой их дальнейшего углубленного изучения на социологическом уровне. Необходимость подобных исследований продиктована самой меняющейся реальностью, в которой меняющийся человек конструирует свой жизненный мир, включенный в соци- окультурную динамику глобального информационного общества и подверженный тенденциям его непрерывной трансформации.

\section{Литература}

1. Алиев Ш.И. Жизненное проектирование российской молодежи в условиях вызовов и рисков информационной эпохи // Гуманитарий Юга России. — 2016. - №1. C. $142-151$.

2. Сердюченко Я. В. Факторы формирования жизненного мира молодой семьи в Ростовской области // Государственное и муниципальное управление. Ученые записки СКАГС. - 2017. - №3. - С. 249-253.

3. Шюч А. Смысловая структура повседневного мира: очерки по феноменологической социологии. - М.: Институт Фонда «Общественное мнение», 2003. - 336 с.

4. Тощенко Ж. Т. Смыслы как качественная и сущностная характеристика социологии жизни // Гуманитарий Юга России. 2017. — №5. - C. 13-28.

5. Волков В.Н. Человек и его жизненные миры [Электронный ресурс]. — URL: http:// culturolog.ru/index2.php?option $=$ com_content\& task $=$ view\&id $=506 \& p o p=1 \&$ page $=0 \&$ Itemid $=5$.

6. Бухариева Н.Г. Самопроектирование: единство самореализации и развития внутреннего мира личности // Педагогическое образование в России. - 2013. - №2. - С. 22-26.

7. Петренко-Лысак А. A. Homo Mobilis в транзит(ив)ном потоке мобильных коммуникаций. [Электронный ресурс]. URL: https://journal-labirint.com/wp-content/ uploads/2015/10/3/Petrenko-Lysak.pdf.

8. Тощенко Ж. Т. Жизненный мир и его смыслы // Социологические исследования. 2016. - №1. - С. 6-17.

9. Алиев Ш.И. Жизненное проектирование российской молодежи в условиях информационной реальности: автореферат дисс. ... док. соц. наук. - Ростов-на-Дону, 2019. — 62 с.

10. Кривошеев В. В. Короткие жизненные проекты: проявление аномии в современном обществе // Социологические исследования. - 2009. - №3. - С. 57-67.

11. Волков Ю.Г. Социология будущего: социологическое знание и социальный проект: монография. - Москва: КНОРУС, 2017. - 178 c. 
12. Мухина К. С. Депрофессионализация российской молодежи: институциональные факторы воспроизводства // Гуманитарий Юга России. - 2017. - №6. - С. 242-250.

13. Верешіагина А.B. Демографическая безопасность России: монография / А.В. Верещагина, С.И. Самыгин, П.В. Станиславский; под ред. П.С. Самыгина. - М.: РУСАЙН, 2016. - $116 \mathrm{c.}$

14. Демиденко A.C. Социальная инфантильность российской молодежи: специфика научного дискурса // Историческая и социально-образовательная мысль. - 2018. №3. - C. 143-149.

15. Большая зарплата или работа по специальности? Пресс-выпуск ВЦИОМ от 15 апреля 2019 г. [Электронный ресурс]. — URL: https://wciom.ru/index.php?id=236\&uid=9655.

16. Тощуенко Ж.Т. Прекариат: от протокласса к новому классу. Монография. Институт социологии ФНИСЦ РАН, РГГУ. - М.: Наука, 2018. - 350 с.

17. Шахбанова М.М., Верещуахина А.В., Самыгин С.И. Жизненный мир молодой семьи и проблемы его формирования в условиях парадоксальной российской реальности// Гуманитарные, социально-экономические и общественные науки. — 2018. - №9. - С.59-66.

\section{References}

1. Aliev Sh. I. Zhiznennoe proektirovanie rossijskoj molodezhi $\mathrm{v}$ uslovijah vyzovov i riskov informacionnoj jepohi [Vital design of Russian youth in the context of challenges and risks of the information age] // Gumanitarij Juga Rossii [Humanities of the South of Russia]. 2016. — №1. — Pp. 142-151.

2. Serdjuchenko Ja. V. Faktory formirovanija zhiznennogo mira molodoj sem'i v Rostovskoj oblasti [Factors of formation of the life world of a young family in the Rostov region] // Gosudarstvennoe i municipal'noe upravlenie. Uchenye zapiski SKAGS [State and municipal administration. Proceedings of the SKAGS]. 2017. — №3. - Pp. 249-253.

3. Shjuc A. Smyslovaja struktura povsednevnogo mira: ocherki po fenomenologicheskoj sociologii [The semantic structure of the everyday world: essays on phenomenological sociology]. Moscow: Institut Fonda «Obshhestvennoe mnenie», 2003. - 336 p.
4. Toshhenko Zh. T. Smysly kak kachestvennaja i sushhnostnaja harakteristika sociologii zhizni [Meanings as a qualitative and essential characteristic of the sociology of life] // Gumanitarij Juga Rossii [Humanities of the South of Russia]. — 2017. - №5. Pp. 13-28.

5. Volkov V.N. Chelovek i ego zhiznennye miry [Man and his life worlds] [Jelektronnyj resurs]. - URL: http://culturolog.ru/index2. php?option $=$ com_content\&task $=$ view\&id $=506$ $\&$ pop $=1 \&$ page $=0 \&$ Itemid $=5$.

6. Buharceva N.G. Samoproektirovanie: edinstvo samorealizacii i razvitija vnutrennego mira lichnosti [Self-projecting: unity of selfrealization and development of the inner world of the individual] // Pedagogicheskoe obrazovanie $\mathrm{v}$ Rossii [Teacher education in Russia]. 2013. - №2. — Pp. 22-26.

7. Petrenko-Lysak A.A. Homo Mobilis v tranzit(iv)nom potoke mobil'nyh kommunikacij [Homo Mobilis in the transit flow of mobile communications]. [Jelektronnyj resurs]. URL: https://journal-labirint.com/wp-content/ uploads/2015/10/3/Petrenko-Lysak.pdf.

8. Toshhenko Zh. T. Zhiznennyj mir i ego smysly [The life world and its meanings] // Sociologicheskie issledovanija [Sociological research]. — 2016. — №1. - Pp. 6-17.

9. Aliev Sh. I. Zhiznennoe proektirovanie rossijskoj molodezhi v uslovijah informacionnoj real'nosti: avtoreferat diss. ... dok. soc. Nauk [Life design of Russian youth in the conditions of information reality: Dr. Sci. (Social) diss.]. Rostov-on-Don, 2019. - 62 p.

10. Krivosheev $V . V$. Korotkie zhiznennye proekty: projavlenie anomii $\mathrm{v}$ sovremennom obshhestve [Short life projects: manifestation of anomie in modern society] // Sociologicheskie issledovanija [Sociological research]. 2009. - №3. - Pp. 57-67.

11. Volkov Ju. G. Sociologija budushhego: sociologicheskoe znanie i social'nyj proekt: monografija [Sociology of the future: sociological knowledge and social project: monograph]. Moscow: KNORUS, 2017. - 178 p.

12. Muhina K.S. Deprofessionalizacija rossijskoj molodezhi: institucional'nye faktory vosproizvodstva [Deprofessionalization of Russian youth: institutional factors of reproduction] // Gumanitarij Juga Rossii [Humanities of the South of Russia]. — 2017. — №6. — Pp. 242-250. 
13. Vereshhagina A.V. Demograficheskaja bezopasnost' Rossii: monografija [Demographic security ofRussia:monograph]/A.V.Vereshhagina, S.I. Samygin, P.V. Stanislavskij; in P.S. Samygin (ed.). - Moscow: RUSAJN, 2016. - 116 p.

14.Demidenko A.S. Social'najainfantil'nost' rossijskoj molodezhi: specifika nauchnogo diskursa [Social infantilism of Russian youth: the specifics of scientific discourse] // Istoricheskaja i social'no-obrazovatel'naja mysl' [Historical and socio-educational thought]. - 2018. №3. - Pp. 143-149.

15. Bol'shaja zarplata ili rabota po special'nosti? Press-vypusk VCIOM ot 15 aprelja 2019 g. [A large salary or a job in the specialty? VTSIOM press release from April 15, 2019] [Jelektronnyj resurs]. — URL: https://wciom.ru/ index.php?id=236\&uid=9655.
16. Toshhenko Zh. T. Prekariat: ot protoklassa k novomu klassu. Monografija. Institut sociologii FNISC RAN, RGGU [Precariat: from a protoclass to a new class. Monograph. Institute of sociology of the Russian Academy of Sciences, RSUH]. - Moscow: Nauka, 2018. - 350 p.

17. Shahbanova M.M., Vereshhagina A.V., Samygin S.I. Zhiznennyj mir molodoj sem'i i problemy ego formirovanija $\mathrm{v}$ uslovijah paradoksal'noj rossijskoj real'nosti [The life world of a young family and the problems of its formation in the conditions of a paradoxical Russian reality] // Gumanitarnye, social'nojekonomicheskie i obshhestvennye nauki [Humanities, socio-economic and social Sciences]. — 2018. — №9. — Pp. 59-66.

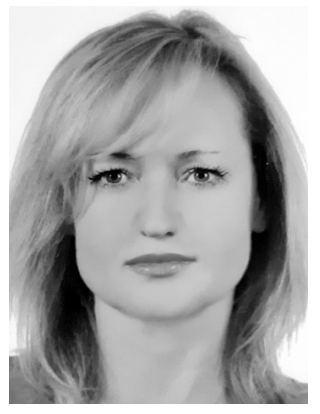

Верещагина Анна Владимировна - доктор социологических наук, доцент, профессор Института социологии и регионоведения Южного федерального университета.

Vereshchagina Anna Vladimirovna - Doctor of Sociological Sciences, Professor, Professor, Institute of Sociology and Regional Studies, Southern Federal University.

344006, г. Ростов-на-Дону, ул. Пушкинская, 160 160 Pushkinskaya st., 344006, Rostov-on-Don, Russia E-mail: anrietta25@mail.ru 


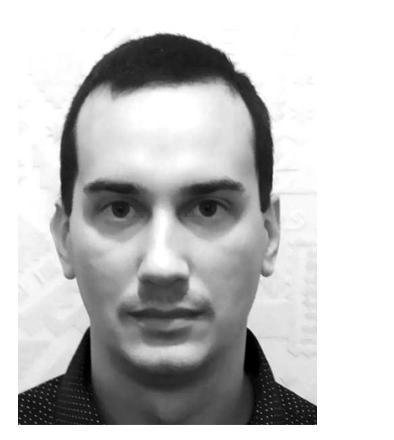

Герасимов Максим Васильевич - соискатель Института социологии и регионоведения Южного федерального университета.

Gerasimov Maxim Vasilievich - Applicant, Institute of Sociology and Regional Studies, Southern Federal University.

344006, г. Ростов-на-Дону, ул. Пушкинская, 160 160 Pushkinskaya st., 344006, Rostov-on-Don, Russia

E-mail:m.gerasimov@ro.ru 